$\cdot$ Original Article·

\title{
SK channels modulate the excitability and firing precision of projection neurons in the robust nucleus of the arcopallium in adult male zebra finches
}

Guo-Qiang Hou, Xuan Pan, Cong-Shu Liao, Song-Hua Wang, Dong-Feng Li

School of Life Science, South China Normal University, Key Laboratory of Ecology and Environmental Science in Higher Education of Guangdong Province, Guangzhou 510631, China

(C) Shanghai Institutes for Biological Sciences, CAS and Springer-Verlag Berlin Heidelberg 2012

\begin{abstract}
Objective Motor control is encoded by neuronal activity. Small conductance $\mathrm{Ca}^{2+}$-activated $\mathrm{K}^{+}$channels (SK channels) maintain the regularity and precision of firing by contributing to the afterhyperpolarization (AHP) of the action potential in mammals. However, it is not clear how SK channels regulate the output of the vocal motor system in songbirds. The premotor robust nucleus of the arcopallium (RA) in the zebra finch is responsible for the output of song information. The temporal pattern of spike bursts in RA projection neurons is associated with the timing of the acoustic features of birdsong. Methods The firing properties of RA projection neurons were analyzed using patch clamp wholecell and cell-attached recording techniques. Results SK channel blockade by apamin decreased the AHP amplitude and increased the evoked firing rate in RA projection neurons. It also caused reductions in the regularity and precision of firing. RA projection neurons displayed regular spontaneous action potentials, while apamin caused irregular spontaneous firing but had no effect on the firing rate. In the absence of synaptic inputs, RA projection neurons still had spontaneous firing, and apamin had an evident effect on the firing rate, but caused no significant change in the firing regularity, compared with apamin application in the presence of synaptic inputs. Conclusion SK channels contribute to the maintenance of firing regularity in RA projection neurons which requires synaptic activity, and consequently ensures the precision of song encoding.
\end{abstract}

Keywords: SK channels; excitability; firing precision; robust nucleus of the arcopallium; zebra finches

\section{Introduction}

Small-conductance $\mathrm{Ca}^{2+}$-activated $\mathrm{K}^{+}$channels (SK channels), widely expressed throughout the nervous system in mammals, are insensitive to changes of membrane potential $^{[1-4]}$. SK channels have three subtypes, SK1, SK2 and SK3, all of which are expressed in the mammalian

Corresponding author: Dong-Feng Li

Tel: +86-20-85211372

E-mail: dfliswx@126.com

Article ID: 1673-7067(2012)03-0271-11

Received date: 2011-11-26; Accepted date: 2012-03-28 brain $^{[1]}$. These channels are activated by rises in intracellular $\mathrm{Ca}^{2+}$ concentration and are specifically blocked by the bee toxin apamin. SK channels contribute to the afterhyperpolarization (AHP) following the action potential ${ }^{[5]}$. In the central nervous system, SK channels are important in controlling the firing frequency of neurons, regulating dendritic excitability, synaptic transmission and synaptic plasticity ${ }^{[6-9]}$. In rat globus pallidus neurons, blockade of SK channels by apamin reduces the AHP amplitude, leading to an increased firing rate. Apamin also causes variation of the firing threshold, which results in impaired firing 
precision. Timing and frequency are important parameters in temporal encoding, thus, blockade of SK channels may influence neuronal encoding activity ${ }^{[10]}$. In hippocampal CA1 neurons, SK2 overexpression decreases long-term potentiation and weakens hippocampus- and amygdaladependent learning, compared to wild-type littermates ${ }^{[11]}$. Therefore, SK channels also play a critical role in learning and memory.

Songbirds learn their songs by imitation and auditory feedback ${ }^{[12]}$, which makes them an excellent model for studying the neural modulation of a complex learned behavior ${ }^{[13]}$. The song system is composed of a discrete set of interconnected nuclei, which underlie song learning and production $^{[14,15]}$. These nuclei and their connections can be divided into two pathways: the vocal motor pathway (VMP) that contributes to song production, and the anterior forebrain pathway (AFP) that is necessary for song learning and plasticity ${ }^{[16,17]}$. The robust nucleus of the arcopallium (RA) in the VMP receives input from the AFP as well, via the lateral magnocellular nucleus of the anterior nidopallium (LMAN) in the AFP ${ }^{[16,18,19]}$. Therefore, the RA, as a premotor nucleus, occupies an important position in the song system, integrating information from both pathways.

RA projection neurons are responsible for transmitting song information to midbrain and brainstem vocal and respiratory structures ${ }^{[20]}$. The temporal pattern of spike bursts in RA projection neurons is associated with the timing of the acoustic features of birdsong. The precise timing of individual spikes is closely associated with stereotypic behavior, which suggests that the song is represented in the RA by a temporal code ${ }^{[21,22]}$. In the zebra finch, apaminsensitive neurons have been identified in the substantia nigra pars compacta $(\mathrm{SNc})$ and ventral tegmental area $(\mathrm{VTA})^{[23]}$, suggesting that SK channels participate in the activities of neurons in the song system. Although it is known that the RA controls the output of song information encoding, the involvement of SK channels is unclear. The present study tested whether and how SK channels modulate the excitability and firing precision of RA projection neurons in adult male zebra finches.

\section{Materials and methods}

2.1 Drugs Apamin, $D L$-2-amino-5-phosphonovaleric acid (APV), 6,7-dinitroquinoxaline-2,3-dione (DNQX) and picrotoxin were from Sigma-Aldrich, St. Louis, MO. Apamin is a noncompetitive selective antagonist of SK channels, and resisted washout from our slice preparation. Unless indicated otherwise, all solutions were continuously bubbled with $95 \% \mathrm{O}_{2}$ and $5 \% \mathrm{CO}_{2}$.

2.2 Slice preparation Adult male zebra finches (Taeniopygia guttata) were obtained from a commercial supplier and housed in group cages. All animal experimental procedures were performed in accordance with the national guidelines and approved by South China Normal University Animal Care Committee. Brain slices were prepared as previously described ${ }^{[24]}$. Briefly, birds were anesthetized with $10 \%$ chloral hydrate and then rapidly decapitated. The brain was dissected into ice-cold, oxygenated $\left(95 \% \mathrm{O}_{2}\right.$ and $5 \% \mathrm{CO}_{2}$ ) slice solution, consisting of (in $\mathrm{mmol} / \mathrm{L}$ ) 62.5 $\mathrm{NaCl}, 5 \mathrm{KCl}, 28 \mathrm{NaHCO}_{3}, 10$ glucose, $1.3 \mathrm{MgSO}_{4} \cdot 7 \mathrm{H}_{2} \mathrm{O}$, $1.26 \mathrm{NaH}_{2} \mathrm{PO}_{4} \cdot \mathrm{H}_{2} \mathrm{O}$, and 248 sucrose ${ }^{[25,26]}$. Standard artificial cerebrospinal fluid (ACSF) consisted of (in $\mathrm{mmol} / \mathrm{L}$ ): $125 \mathrm{NaCl}, 2.5 \mathrm{KCl}, 25 \mathrm{NaHCO}_{3}, 1.27 \mathrm{NaH}_{2} \mathrm{PO}_{4} \cdot \mathrm{H}_{2} \mathrm{O}, 1.2$ $\mathrm{MgSO}_{4} \cdot 7 \mathrm{H}_{2} \mathrm{O}, 2 \mathrm{CaCl}_{2}$, and 25 glucose, and the osmolarity was adjusted with sucrose to $350 \mathrm{mOsm}^{[25]}$. Coronal brain slices (250-300 $\mu \mathrm{m}$ thick) containing the RA were cut with a vibrating microtome (NVSLM1, WPI, Sarasota, FL) and collected in standard $\operatorname{ACSF}\left(37^{\circ} \mathrm{C}\right)$. Slices were allowed to recover in the holding chamber for at least $1 \mathrm{~h}$ and cooled to room temperature before recordings.

2.3 Electrophysiological recordings Electrophysiological recordings were performed at room temperature (24$28^{\circ} \mathrm{C}$ ) in oxygenated ACSF. The RA and the surrounding tissues were distinguished under a BX51WI microscope with a DIC-IR video camera (Olympus, Japan). Recording pipettes were fabricated from borosilicate glass (Sutter Instruments, Novato, CA) using a Flaming-Brown puller (model P-97, Sutter Instruments) and were filled with pipette solution containing (in mmol/L): $120 \mathrm{KMeSO}_{4}$, $5 \mathrm{NaCl}, 10$ HEPES, 2 EGTA, 2 ATP, and $0.3 \mathrm{GTP}(\mathrm{pH}$ 7.2-7.4, $340 \mathrm{mOsm}$ ). The recording pipettes, which had resistances of 4-7 M $\Omega$, were positioned using an integrated 
motorized control system (Sutter Instruments). Wholecell and cell-attached recordings were made using standard techniques.

The two cell types in the RA, glutamatergic projection neurons and GABAergic interneurons, were distinguished according to their distinct electrophysiological properties. The former displayed regular spontaneous firing, and could be induced to generate a time-dependent inward rectification by hyperpolarizing current injection, while the latter displayed no spontaneous firing in the resting state. Moreover, a depolarizing current injection induced a higher firing rate and a less regular frequency in interneurons than in projection neurons ${ }^{[27,28]}$.

2.4 Data analysis All numerical data are presented as mean \pm SEM. Measurements of firing rate, interspike interval (ISI), intercurrent interval (ICI) and spike threshold were made with Clampfit 9.2 software (Axon Instruments, Union City, CA). The coefficient of variation (CV) was determined as the value of standard deviation/mean. The AHP amplitude was quantified as the difference between spike threshold and the lowest point of the AHP. Data were graphed using OriginPro 8 (OriginLab, Northampton, MA). All statistics were calculated using Excel and OriginPro 8 . The two-tailed paired-sample $t$-test was used to evaluate differences between groups. Differences were considered statistically significant when $P<0.05$.

\section{Results}

3.1 SK channel blockade reduces the AHP amplitude and increases the firing rate of $\mathrm{RA}$ projection neurons

To test whether SK channels contribute to the AHP and regulate excitatory activity in RA projection neurons in adult male zebra finches, we made plots of injected currents from 0 to $200 \mathrm{pA}$ for $500 \mathrm{~ms}$ at $50 \mathrm{pA}$ steps and $10 \mathrm{~s}$ intervals, against mean firing rate (Fig. 1A). Apamin (100 $\mathrm{nmol} / \mathrm{L})$, a specific antagonist of SK channels, caused an increase in the evoked firing rate $(P<0.05, n=10)$ (Fig. $1 \mathrm{~B})$, as a result of which apamin reduced the amplitude of the AHP. The ISI was shortened because the AHP depth was decreased (Fig. 1C). The average AHP amplitude was reduced after $100 \mathrm{nmol} / \mathrm{L}$ apamin application, in particular at 100,150 and $200 \mathrm{pA}(P<0.05, n=8)$ (Fig. 1D). These results implied that SK channels contribute to the excitability of RA projection neurons and might regulate the output of birdsong.

On the other hand, to test whether SK channels also contribute to activity below the membrane potential in RA projection neurons, we compared the current-voltage (I-V) relationships in control and $100 \mathrm{nmol} / \mathrm{L}$ apamin treatment groups (Fig. 1E). Apamin had no influence on the slope of the $I-V$ curve by linear fit (Fig. $1 \mathrm{~F}$ ), suggesting that SK channels were activated only by $\mathrm{Ca}^{2+}$ influx when the membrane potential was depolarized in RA projection neurons.

\subsection{SK channel blockade disrupts firing regularity of} RA projection neurons The AHP, an essential part of the action potential, allows the recovery of ion channels from inactivation in each cycle. The spontaneous firing became more irregular after $100 \mathrm{nmol} / \mathrm{L}$ apamin (Fig. 2A). Apamin significantly increased the $\mathrm{CV}$ of ISIs induced by $\geq 100 \mathrm{pA}$ current injection $(P<0.05, n=10)$ (Fig. 2B). The CV of ISIs of spontaneous firing (no current injection) was higher than that of evoked firing in control solutions. Apamin did not cause a significant increase in the CV of ISIs of spontaneous firing $(0.1385 \pm 0.037$ in control vs $0.1643 \pm 0.0282$ in apamin, $n=10$ ) (Fig. 2B).

The production of spontaneous action potentials is more complex than that by current injection. To test the effects of apamin on the spontaneous firing of each neuron, we made plots of mean firing rate against the CV of ISIs. Spontaneous firing was recorded for at least $80 \mathrm{~s}$. The results showed that apamin $(100 \mathrm{nmol} / \mathrm{L})$ had no significant effect on the mean spontaneous firing rate or the $\mathrm{CV}$ of ISIs $(n=7)$ (Fig. 2D). Besides, we found that spontaneous firing rates gradually declined with time in controls, which might be because during whole-cell recording, the electrode tip inevitably broke part of the cell membrane, weakening the cell and reducing the spontaneous firing rate. To confirm the effect of apamin on the spontaneous activity of RA projection neurons, we recorded spontaneous currents in the cell-attached voltage-clamp configuration (Fig. 2C). On average, apamin had no effect on the mean spontaneous current firing rate $(7.18 \pm 0.87 \mathrm{~Hz}$ in control $v s 7.30 \pm$ 


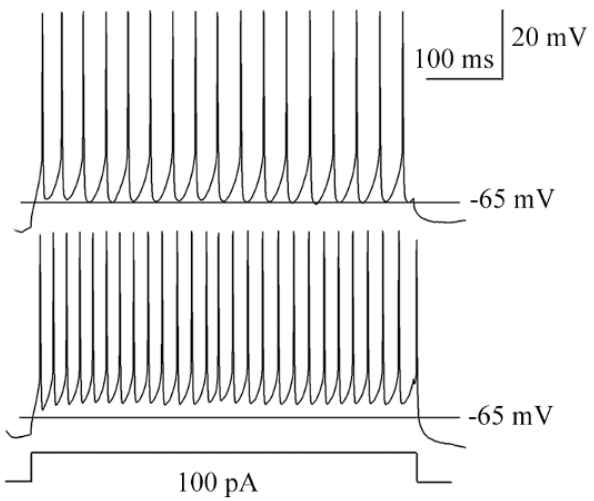

- Control
- - Apamin $100 \mathrm{nmol} / \mathrm{L} \quad 5 \mathrm{~ms}$

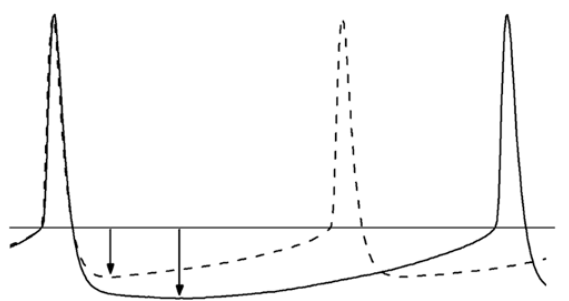

$\mathrm{E}$
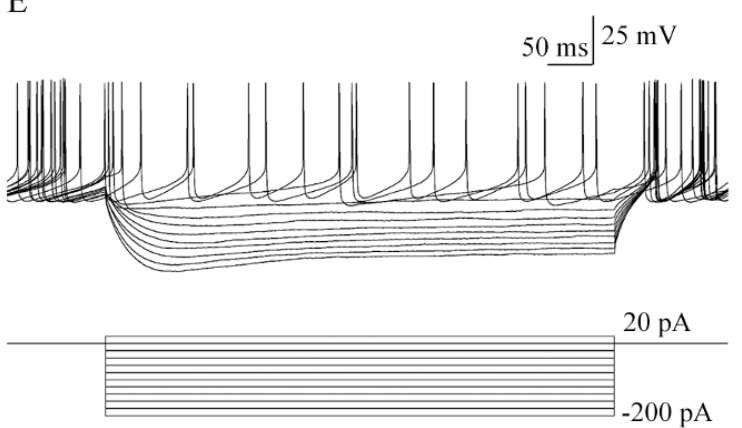

D

$$
\text { B } 100] \begin{aligned}
& - \text { - Control } \\
& \quad-\text { - Apamin } 100 \mathrm{nmol} / \mathrm{L}
\end{aligned}
$$
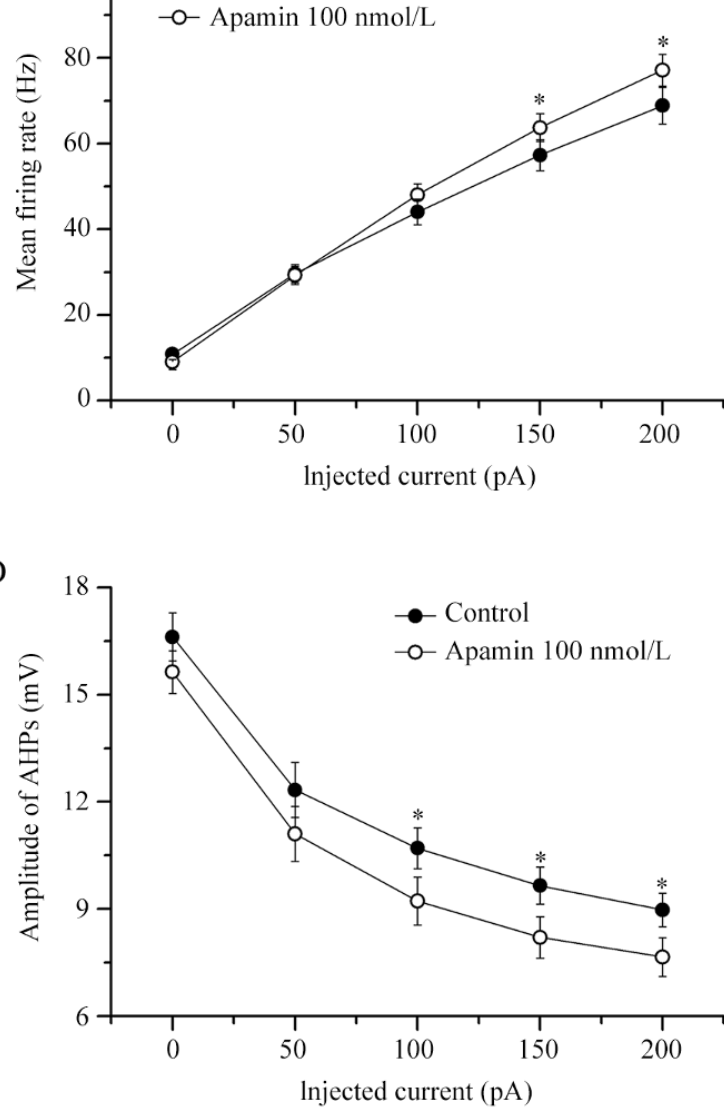

$\mathrm{F}$

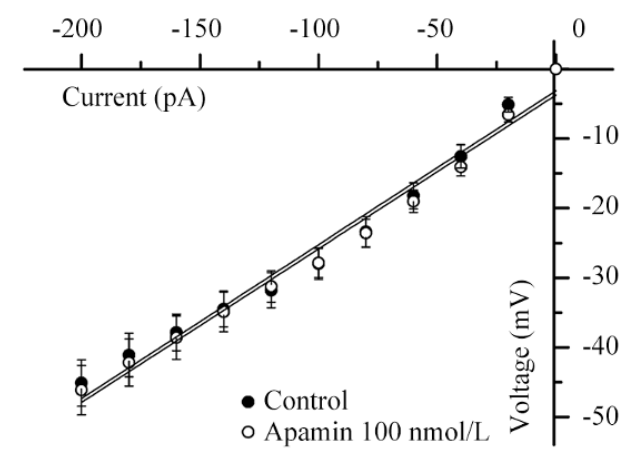

Fig. 1. Blockade of SK channels reduces the amplitude of afterhyperpolarizations (AHPs) and increases the firing rate in RA projection neurons. A: Sample traces of firing in response to $100 \mathrm{pA}$ current injection $(500 \mathrm{~ms})$ in control ACSF (upper) and with apamin (lower). The firing rate was increased by $100 \mathrm{nmol} / \mathrm{L}$ apamin, from $34.00 \mathrm{~Hz}$ in control to $53.36 \mathrm{~Hz}$ in apamin. B: Plot of firing frequency versus injected current for a sample of 10 neurons. Apamin application caused an increase in firing rate, but a small decrease without current injection (i.e., spontaneous firing rate) $(* P<0.05, n=10)$. C: The AHP amplitude was reduced by $100 \mathrm{nmol} / \mathrm{L}$ apamin. Action potentials evoked by $100 \mathrm{pA}$ current injection are overlaid to show the change of AHP by apamin application. The arrows show the depth of AHP. The spikes in control are shown as a solid line, and those in apamin as a dashed line. D: Plot of AHP amplitude versus injected current. Apamin caused a significant decrease in AHP $\left({ }^{*} P<0.05, n=8\right)$. E: Sample traces in response to hyperpolarizing current injection, from -200 pA to $10 \mathrm{pA}$ for $600 \mathrm{~ms}$ at $20 \mathrm{pA}$ steps and $2 \mathrm{~s}$ intervals. F: $I-V$ relationships in control and $100 \mathrm{nmol} / \mathrm{L}$ apamin groups. The slope of the $I-V$ curve was not changed after apamin application, $0.221 \pm 0.0109$ in control and $0.2208 \pm 0.0098$ in apamin $(n=10)$. The average in control is shown as filled circles, and that in apamin as open circles. 
A
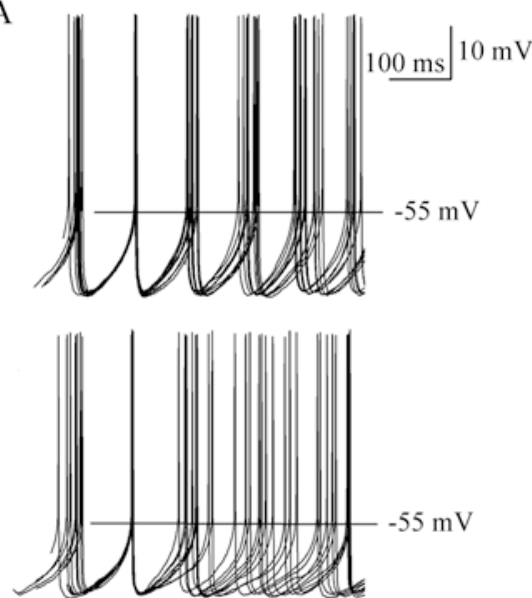

B

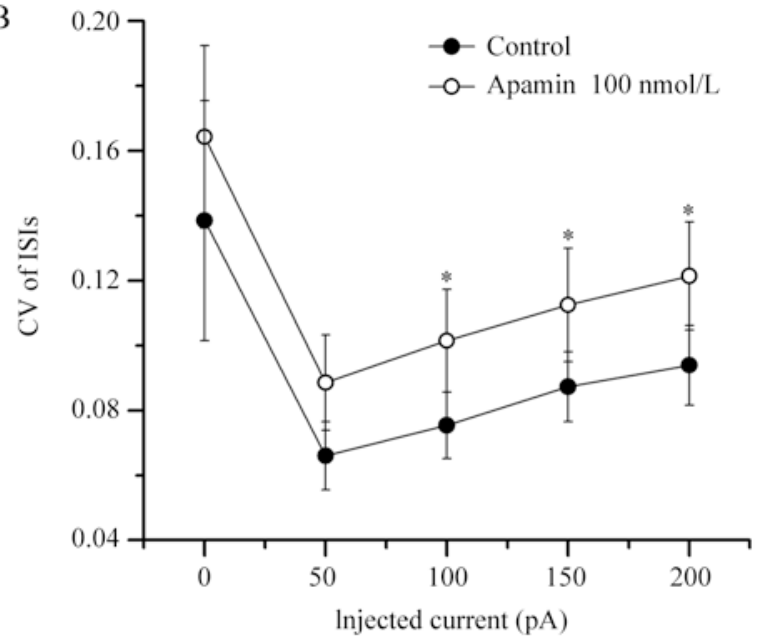

C
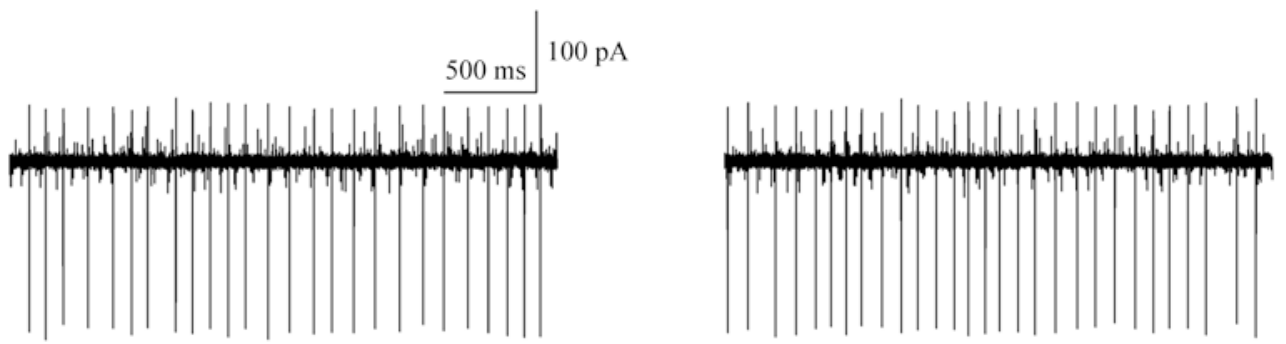

D

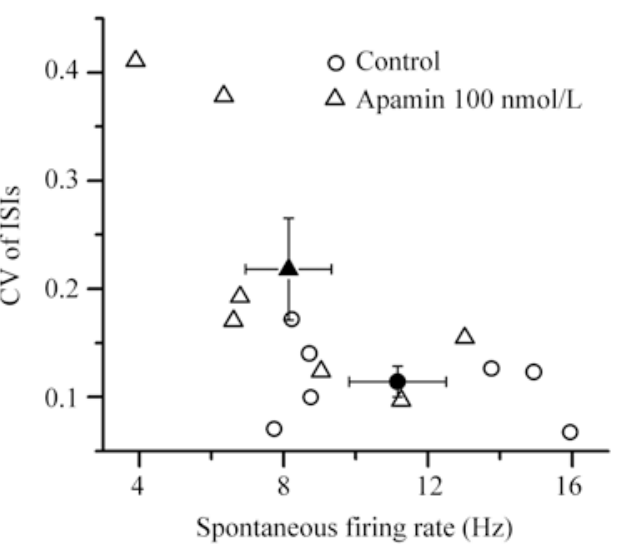

E

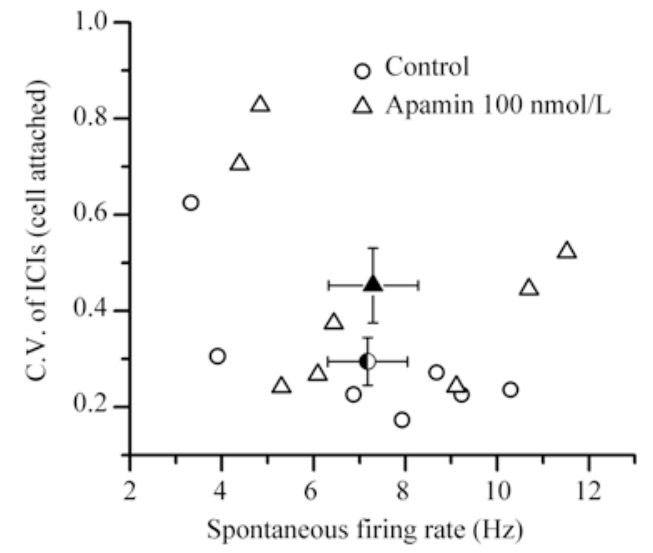

Fig. 2. SK channels maintain the regularity of firing in RA projection neurons. A: Ten traces of spontaneous action potentials recorded in the whole-cell configuration are aligned and superimposed to show the regularity of firing. In control solution (upper), the action potentials repeated in a regular manner. In $100 \mathrm{nmol} / \mathrm{L}$ apamin (lower), the spontaneous firing became irregular. B: SK channel blockade disrupted the firing regularity of evoked action potentials. The average coefficient of variation (CV) of interspike intervals (ISIs) induced by $\geq 100$ pA current injection was increased by $100 \mathrm{nmol} / \mathrm{L}$ apamin $(* P<0.05, n=10)$. C: Examples of spontaneous currents recorded in the cell-attached voltage-clamp configuration, in control (left) and in $100 \mathrm{nmol} / \mathrm{L}$ apamin (right). D: Measurements of spontaneous firing recorded in the whole-cell configuration, showing no statistically significant difference in mean spontaneous firing rate and CV of ISIs $(n=7)$. The spontaneous firing of each RA cell was recorded for 80-120 s. Individual cells are shown as open circles in control and triangles in apamin, and the average of each group is shown as a filled circle in control and triangle in apamin. E: Measurements of spontaneous currents recorded in the cell-attached configuration, showing no difference in mean spontaneous firing rate $(n=8)$, but a marked increase in the $\mathrm{CV}$ of $\mathrm{ICIs}(P<0.05, n=8)$. Individual cells are shown as open circles in control and triangles in apamin, and the average in apamin is shown as a filled triangle. An open circle is covered by the filled circle, so the average in control is shown as a half-filled circle. 
$0.96 \mathrm{~Hz}$ in apamin, $n=8$ ). On the contrary, the CV of ICIs was distinctly increased from $0.2946 \pm 0.0495$ in controls to $0.4532 \pm 0.0777$ in the apamin group $(P<0.05, n=8)$ (Fig. 2E). These results suggest that SK channels enhance the regularity of spontaneous activity in RA projection neurons.

SK channel blockade reduced AHP depth and increased the firing rate, but some voltage-gated $\mathrm{Na}^{+}$channels may not completely recover from inactivation before the start of the next action potential. If so, the threshold of the next action potential would be variable and unstable. To test this hypothesis, we analyzed the change of spike threshold after $100 \mathrm{nmol} / \mathrm{L}$ apamin application.
Apamin caused a frequency-dependent depolarization in spike threshold and increased the threshold variability in the whole-cell configuration (Fig. 3A). The average spike threshold by $200 \mathrm{pA}$ current injection was increased by $100 \mathrm{nmol} / \mathrm{L}$ apamin $(P<0.05, n=8)$ (Fig. 3B). But the spontaneous spike threshold had a small hyperpolarization, probably resulting from the decrease of spontaneous firing rate. Apamin also led to a frequency-dependent increase in the average $\mathrm{CV}$ of the evoked spike threshold $(P<0.05, n=$ 8) (Fig. 3C). The variability of spike threshold determines the regularity of spike firing. These results indicate that SK channels ensure the precision of spike threshold and firing regularity by modifying the AHP.
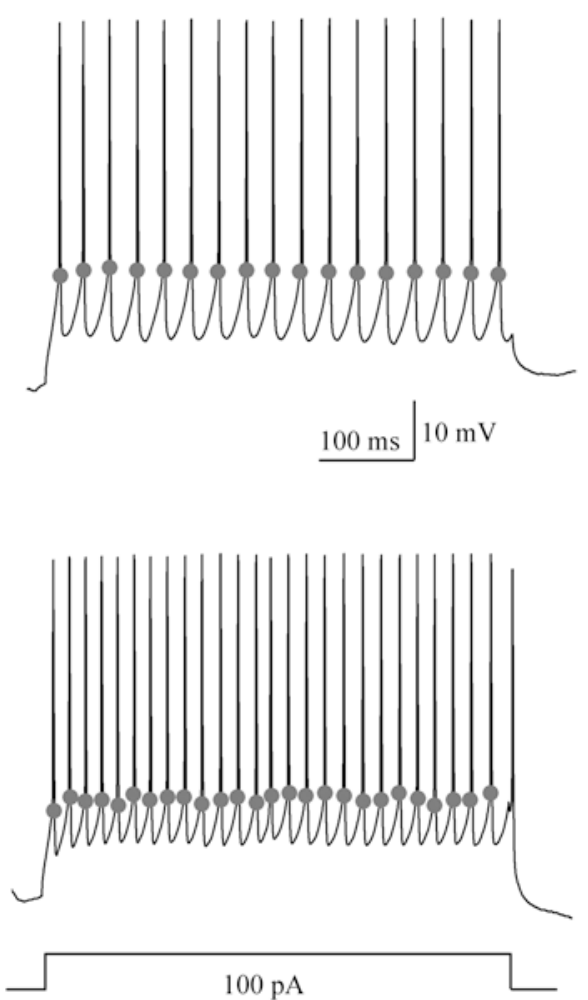

B
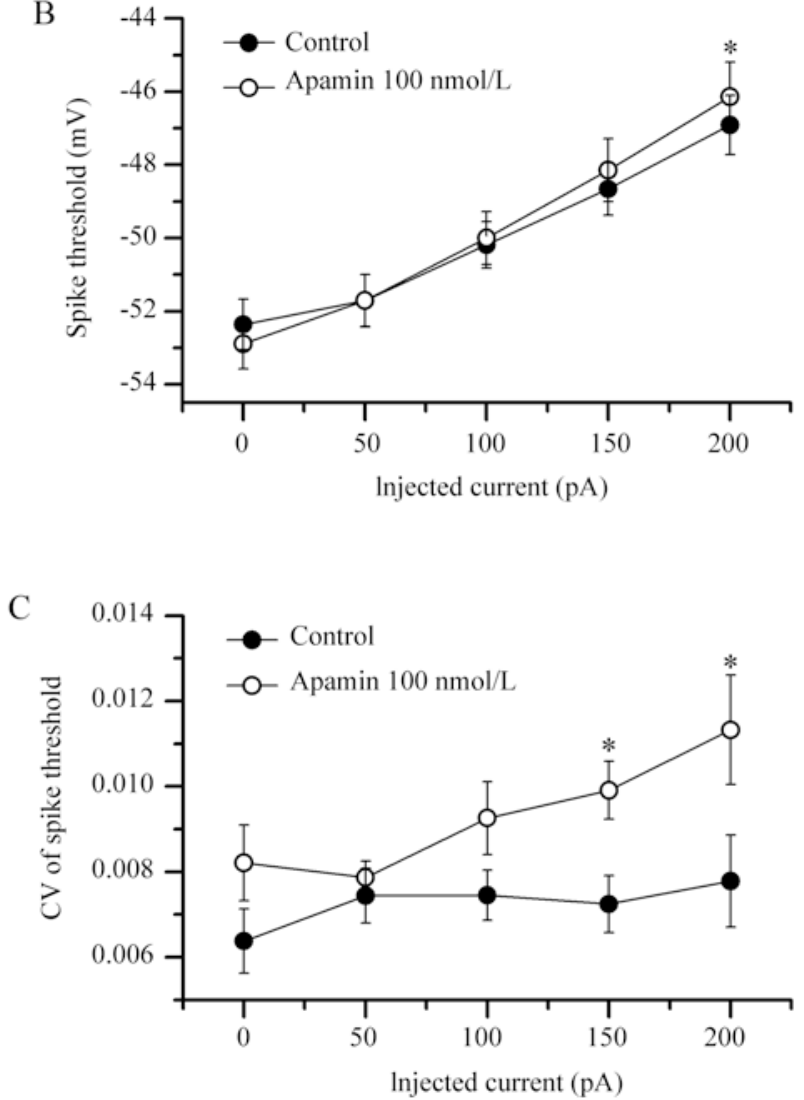

Fig. 3. SK channels enhance the precision of spike threshold to ensure regularity of firing. A: Examples of action potential traces induced by 100 pA current injection $(500 \mathrm{~ms})$ from an $\mathrm{RA}$ projection neuron recorded in the whole-cell configuration before (upper) and after (lower) $100 \mathrm{nmol} / \mathrm{L}$ apamin application. Thresholds are shown as grey dots. B: Effect of $100 \mathrm{nmol} / \mathrm{L}$ apamin on spike threshold. The threshold of evoked spikes had a frequency-dependent depolarization ( ${ }^{P}<0.05, n=8$ ), but the threshold of spontaneous firing (no current injection) had a small hyperpolarization $(n=8)$, which was related to the decline of spontaneous firing rate as shown in Fig. $2 D$. C: Effect of $100 \mathrm{nmol} / \mathrm{L}$ apamin on the precision of spike threshold. Apamin caused a frequency-dependent increase in the coefficient of variation (CV) of evoked spike threshold $(* P<0.05, n=8)$. 


\subsection{Effect of apamin on neurons without spontane-} ous synaptic inputs In songbirds, the RA receives dual synaptic inputs from the higher vocal center (HVC) and the LMAN. Both are excitatory glutamatergic, but have distinct postsynaptic properties. The HVC-RA input is largely mediated by the $\alpha$-amino-3-hydroxy-5-methyl-4-
A

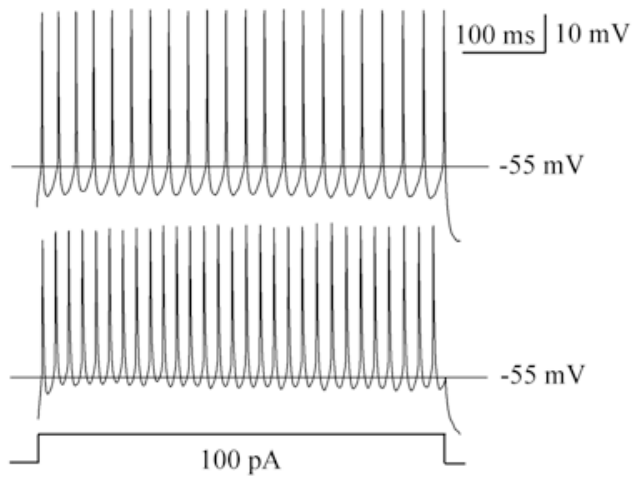

C

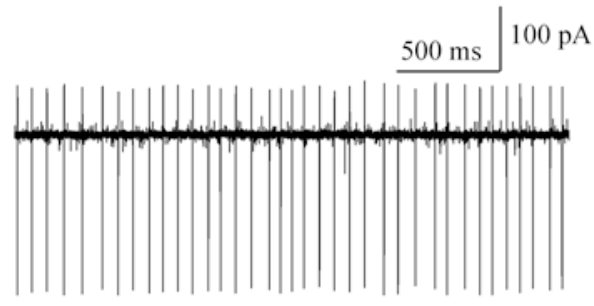

D

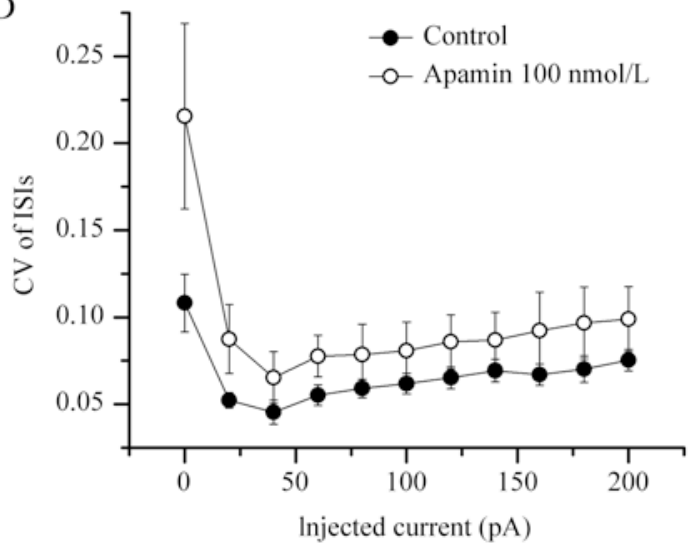

B
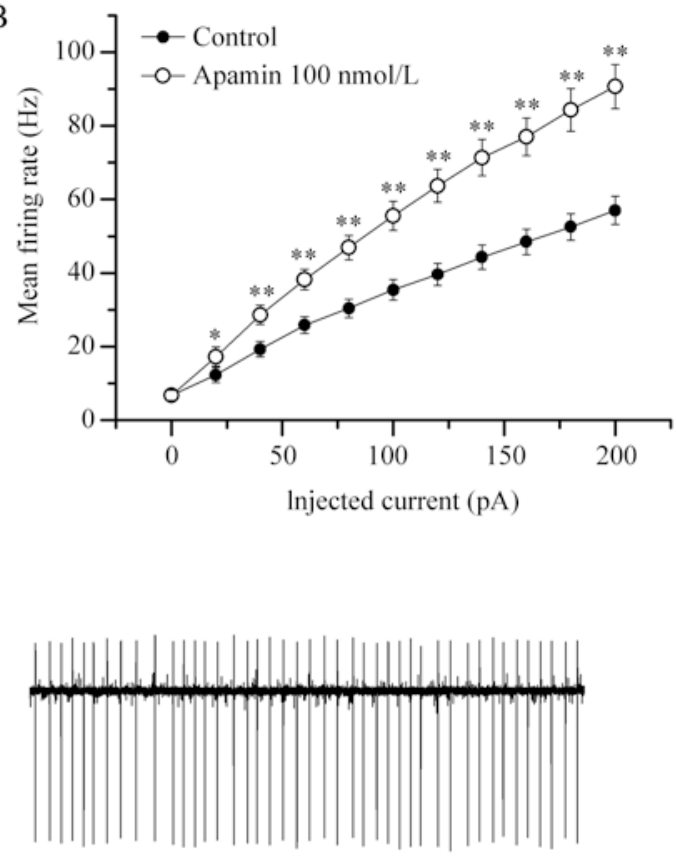

E

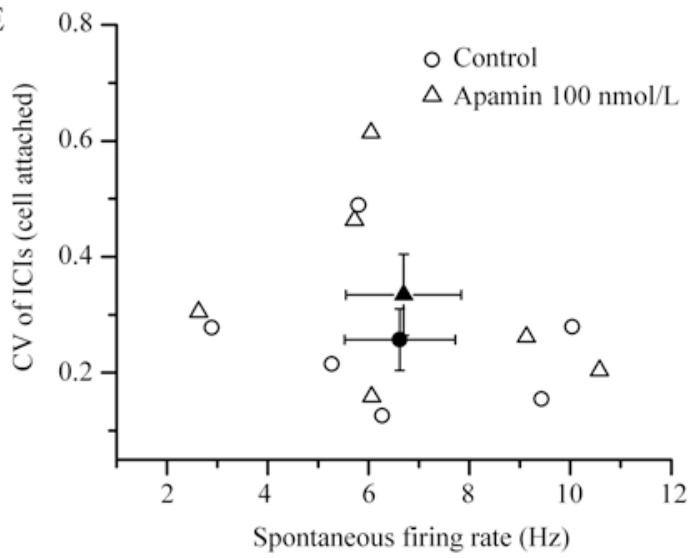

Fig. 4. Blockade of SK channels increases the firing rate and decreases the regularity of firing in the absence of synaptic inputs. A: Sample traces of firing in response to $100 \mathrm{pA}$ current injection $(500 \mathrm{~ms})$ in control ACSF (upper) and with $100 \mathrm{nmol} / \mathrm{L}$ apamin (lower) in the presence of $50 \mu \mathrm{mol} / \mathrm{L}$ APV, $20 \mu \mathrm{mol} / \mathrm{L}$ DNQX and $150 \mu \mathrm{mol} / \mathrm{L}$ picrotoxin. The firing rate was clearly increased by apamin, from $42.73 \mathrm{~Hz}$ in control to $58.61 \mathrm{~Hz}$ in apamin. B: In the presence of $50 \mu \mathrm{mol} / \mathrm{L} \mathrm{APV}, 20 \mu \mathrm{mol} / \mathrm{L}$ DNQX and $150 \mu \mathrm{mol} / \mathrm{L}$ picrotoxin, $100 \mathrm{nmol} / \mathrm{L}$ apamin induced an increase in the firing rate $(* P<$ $0.05, * * P<0.01, n=6$ ). C: Examples of spontaneous currents recorded in the cell-attached voltage-clamp configuration in the presence of APV, DNQX and picrotoxin, in control (left) and in $100 \mathrm{nmol} / \mathrm{L}$ apamin (right) groups. D: Apamin had no effect on the coefficient of variation (CV) of interspike intervals (ISIs) in the presence of APV, DNQX and picrotoxin $(n=6)$. E: Measurements of spontaneous currents recorded in the cellattached configuration in the presence of APV, DNQX and picrotoxin showed no difference in mean spontaneous firing rate or the CV of ICIs ( $n=$ 6). Individual cells are shown as open circles in control and triangles in apamin, and the average of each group is shown as a filled circle in control and a filled triangle in apamin. 
isoxazolepropionic acid receptor (AMPAR), whereas the LMAN-RA input is almost completely mediated by the $\mathrm{N}$-methyl- $D$-aspartic acid receptor (NMDAR) ${ }^{[29-32]}$. The LMAN is the last output nucleus of the anterior forebrain pathway that is necessary for song learning and plasticity $^{[15-17]}$. RA projection neurons also receive glutamatergic inputs from the axon collaterals of other RA projection neurons and GABAergic inputs from local interneurons ${ }^{[19]}$. These synaptic inputs may affect the neuronal responses to apamin.

To test whether the effect of SK channel blockade on RA projection neuronal firing was dependent on synaptic activity, we made plots of depolarizing current from 0 to $200 \mathrm{pA}$ for $500 \mathrm{~ms}$ at $20 \mathrm{pA}$ steps and $10 \mathrm{~s}$ intervals, against the mean firing rate or $\mathrm{CV}$ of ISIs in the presence of $50 \mu \mathrm{mol} / \mathrm{L}$ APV (an NMDAR blocker), $20 \mu \mathrm{mol} / \mathrm{L}$ DNQX (a non-NMDAR blocker) and $150 \mu \mathrm{mol} / \mathrm{L}$ picrotoxin (a GABA receptor blocker) (Fig. 4). Apamin (100 $\mathrm{nmol} / \mathrm{L}$ ) caused a notable increase in the average firing rate when the neurons were injected with $\geq 40$ pA currents $(P<$ $0.01, n=6$ ) (Fig. 4B), but had no significant effect on the CV of ISIs $(n=6)$ (Fig. 4D). Furthermore, to confirm the effect of apamin on spontaneous activity in the absence of synaptic inputs, we recorded spontaneous currents in the cell-attached voltage-clamp configuration in the presence of $50 \mu \mathrm{mol} / \mathrm{L} \mathrm{APV}, 20 \mu \mathrm{mol} / \mathrm{L}$ DNQX and $150 \mu \mathrm{mol} / \mathrm{L}$ picrotoxin (Fig. 4C). On average, apamin had no effect on the mean spontaneous current firing rate $(6.62 \pm 1.1 \mathrm{~Hz}$ in control, $6.7 \pm 1.15 \mathrm{~Hz}$ in apamin, $n=6$ ) or the $\mathrm{CV}$ of ICIs $(0.257 \pm 0.0529$ in control, $0.3345 \pm 0.0704$ in apamin, $n$ =6) (Fig. 4E). These results demonstrated that the effect of postsynaptic SK channels on controlling the firing rate is independent of synaptic activity, but the effect on firing precision may be influenced by such inputs.

\section{Discussion}

In this study, the contribution of SK channels to the modulation of the excitability and firing precision of RA projection neurons in zebra finches was investigated. The results showed that SK channels controlled the firing rate, even without synaptic inputs. SK channels also main- tained the firing regularity and precision, which requires synaptic activity in the RA. These results are supported by the findings in rat globus pallidus (GP) neurons ${ }^{[10]}$. Both RA projection neurons and rat GP neurons have rhythmic spontaneous action potentials, even in the absence of synaptic inputs ${ }^{[10,33-38]}$. In the RA, SK channels contribute to the AHP, and provide time for $\mathrm{Na}^{+}$channels to recover from inactivation ${ }^{[8,39]}$. They also ensure the firing regularity and precision in the presence of synaptic activity. RA projection neurons may encode birdsong information through changes in spike time and firing rate.

The present study showed that SK channel blockade caused a small reduction in the AHP amplitude of spontaneous action potentials, while the spontaneous firing rate was also reduced in the whole-cell configuration. This may be due to the lesion caused by rupturing part of the cell membrane. RA projection neurons fired action potentials autonomously without synaptic transmission. This may be induced by the activity of subthreshold-activated $\mathrm{Na}^{+}$ and $\mathrm{K}^{+}$channels, as suggested in rat GP neurons. These ion channels bring the membrane potential to threshold on each cycle of oscillation ${ }^{[10,40]}$. After breaking the cell membrane in the whole-cell configuration, changes in intracellular constituents may disrupt the mechanism of membrane potential oscillation. Cell-attached recording provides a way to record spontaneous firing activity without breaking the membran $\mathrm{e}^{[41]}$. Therefore, the results from cell-attached recording suggest that SK channels maintain the regularity of spontaneous firing, which is dependent on synaptic activity.

In the absence of synaptic inputs, SK channels still contributed to the AHP, suggesting that the postsynaptic SK channels modulate the excitability of RA projection neurons. Recent studies in rats indicate that SK channels are located postsynaptically ${ }^{[7,42-44]}$. Blockade of SK channels has no influence on neurotransmitter release in hippocampal CA1 pyramidal neurons ${ }^{[6]}$. In songbirds, the activities of individual RA projection neurons probably encode a whole song precisely ${ }^{[45]}$. Precision in behavior is reflected in precision in neuronal control elements ${ }^{[22]}$. Thus, postsynaptic SK channels in the RA ensure that the 
bird can produce a stereotyped song. In the presence of APV, DNQX and picrotoxin, however, the change of firing regularity was not statistically significant, suggesting that not only postsynaptic SK channels, but also synaptic activity may contribute to the firing regularity of RA projection neurons.

During the action potential, SK channels are activated by $\mathrm{Ca}^{2+}$ influx through voltage-gated $\mathrm{Ca}^{2+}$ channels ${ }^{[5,8,44]}$. Furthermore, it has been reported that $\mathrm{Ca}^{2+}$ influx through postsynaptic NMDARs also activates SK channels, especially in dendritic spines. SK channels re-polarize the membrane potential and drive $\mathrm{Mg}^{2+}$ to block the NMDAR channels. The $\mathrm{Mg}^{2+}$ lock limits NMDAR-dependent $\mathrm{Ca}^{2+}$ influx. Thus, SK channels and NMDARs form a $\mathrm{Ca}^{2+}-\mathrm{me}-$ diated negative feedback loop in dendritic spines ${ }^{[6,9,42,46-48]}$. In excitatory synaptic transmission, SK channels, activated by $\mathrm{Ca}^{2+}$ influx through NMDARs, contribute to the excitatory postsynaptic potential (EPSP). $\mathrm{Ca}^{2+}$ influx through NMDARs is essential for multiple forms of synaptic plasticity, including long-term potentiation and long-term depression ${ }^{[49-52]}$. The SK channel blocker apamin causes an increase in the EPSP, which requires NMDAR activity $^{[7,42-44]}$. In the present study, SK channels modulated the excitability and maintained the regularity of firing in RA projection neurons of zebra finches. The NMDAR - SK channel negative feedback loop may have an effect on the complex process of song learning and plasticity in songbirds. Therefore, in addition to contributing to the precision of song encoding, it is possible that SK channels coordinate with NMDARs to modulate synaptic transmission and plasticity in the song system of songbirds.

Acknowledgements: This work was supported by grants from the National Natural Science Foundation of China (30970363 and 31172092). The authors thank Drs. Li Yang and Qili Feng for critical reading and helpful comments on this manuscript.

\section{References:}

[1] Köhler M, Hirschberg B, Bond CT, Kinzie JM, Marrion NV, Maylie $\mathrm{J}$, et al. Small-conductance, calcium-activated potassium channels from mammalian brain. Science 1996, 273: 1709-1714.

[2] Stocker M, Pedarzani P. Differential distribution of three $\mathrm{Ca}^{2+}$ activated $\mathrm{K}^{+}$channel subunits, SK1, SK2, and SK3, in the adult rat central nervous system. Mol Cell Neurosci 2000, 15: 476-493.

[3] Sah P, Faber ES. Channels underlying neuronal calcium-activated potassium currents. Prog Neurobiol 2002, 66: 345-353.

[4] Sailer CA, Hu H, Kaufmann WA, Trieb M, Schwarzer C, Storm JF, et al. Regional differences in distribution and functional expression of small-conductance $\mathrm{Ca}^{2+}$-activated $\mathrm{K}^{+}$channels in rat brain. $\mathrm{J}$ Neurosci 2002, 22: 9698-9707.

[5] Castle NA. Recent advances in the biology of small conductance calcium-activated potassium channels. In: Darbon H, Sabatier JM (Eds.). Perspectives in Drug Discovery and Design: Animal Toxins and Potassium Channels. Dordrecht: Kluwer Academic Publishers, 1999, 15-16: 131-154.

[6] Stackman RW, Hammond RS, Linardatos E, Gerlach A, Maylie J, Adelman JP, et al. Small conductance $\mathrm{Ca}^{2+}$-activated $\mathrm{K}^{+}$channels modulate synaptic plasticity and memory encoding. J Neurosci 2002, 22: 10163-10171.

[7] Faber ES, Delaney AJ, Sah P. SK channels regulate excitatory synaptic transmission and plasticity in the lateral amygdala. Nat Neurosci 2005, 8: 635-641.

[8] Faber ES, Sah P. Functions of SK channels in central neurons. Clin Exp Pharmacol Physiol 2007, 34: 1077-1083.

[9] $\mathrm{Gu} \mathrm{N}, \mathrm{Hu} \mathrm{H}$, Vervaeke K, Storm JF. SK $\left(\mathrm{K}_{\mathrm{Ca}} 2\right)$ channels do not control somatic excitability in CA1 pyramidal neurons but can be activated by dendritic excitatory synapses and regulate their impact. J Neurophysiol 2008, 100: 2589-2604.

[10] Deister CA, Chan CS, Surmeier DJ, Wilson CJ. Calcium-activated SK channels influence voltage-gated ion channels to determine the precision of firing in globus pallidus neurons. J Neurosci 2009, 29: $8452-8461$.

[11] Hammond RS, Bond CT, Strassmaier T, Ngo-Anh TJ, Adelman JP, Maylie J, et al. Small-conductance $\mathrm{Ca}^{2+}$-activated $\mathrm{K}^{+}$channel type 2 (SK2) modulates hippocampal learning, memory, and synaptic plasticity. J Neurosci 2006, 26: 1844-1853.

[12] Mooney R. Neural mechanisms for learned birdsong. Learn Mem 2009, 16: 655-669.

[13] Zeigler HP, Marler PR (Eds.). Behavioral Neurobiology of Birdsong. Annals of the New York Academy of Sciences. New York, NY: New York Academy of Sciences, 2004, 1016: 1-786.

[14] Nottebohm F, Stokes TM, Leonard CM. Central control of song in the canary, Serinus canarius. J Comp Neurol 1976, 165: 457-486.

[15] Nottebohm F. The neural basis of birdsong. PLoS Biol 2005, 3: e164.

[16] Bottjer SW, Miesner EA, Arnold AP. Forebrain lesions disrupt development but not maintenance of song in passerine birds. Science 1984, 224: 901-903. 
[17] Scharff C, Nottebohm F. A comparative study of the behavioral deficits following lesions of various parts of the zebra finch song system: implications for vocal learning. J Neurosci 1991, 11: 2896 2913.

[18] Kao MH, Doupe AJ, Brainard MS. Contributions of an avian basal ganglia-forebrain circuit to real-time modulation of song. Nature 2005, 433: 638-643.

[19] Sizemore M, Perkel DJ. Noradrenergic and GABA B receptor activation differentially modulate inputs to the premotor nucleus RA in zebra finches. J Neurophysiol 2008, 100: 8-18.

[20] Wild JM. Descending projections of the songbird nucleus robustus archistriatalis. J Comp Neurol 1993, 338: 225-241.

[21] Yu AC, Margoliash D. Temporal hierarchical control of singing in birds. Science 1996, 273: 1871-1875.

[22] Chi Z, Margoliash D. Temporal precision and temporal drift in brain and behavior of zebra finch song. Neuron 2001, 32: 899-910.

[23] Gale SD, Perkel DJ. Physiological properties of zebra finch ventral tegmental area and substantia nigra pars compacta neurons. J Neurophysiol 2006, 96: 2295-2306.

[24] Liao SQ, Liu XL, Li DF. Whole-cell recording of the robust nucleus of the arcopallium neurons in the adult zebra finch. Neural Regen Res 2009, 4: 623-628.

[25] Bottjer SW. Silent synapses in a thalamo-cortical circuit necessary for song learning in zebra finches. J Neurophysiol 2005, 94 : 3698-3707.

[26] Wang J, Hessler NA. Coordination of presynaptic and postsynaptic maturation in a zebra finch forebrain motor control nucleus during song learning. Eur J Neurosci 2006, 24: 2859-2869.

[27] Spiro JE, Dalva MB, Mooney R. Long-range inhibition within the zebra finch song nucleus RA can coordinate the firing of multiple projection neurons. J Neurophysiol 1999, 81: 3007-3020.

[28] Liao SQ, Hou GQ, Liu XL, Long C, Li DF. Electrophysiological properties of neurons in the robust nucleus of the arcopallium of adult male zebra finches. Neurosci Lett 2011, 487: 234-239.

[29] Kubota M, Saito N. NMDA receptors participate differentially in two different synaptic inputs in neurons of the zebra finch robust nucleus of the archistriatum in vitro. Neurosci Lett 1991, 125: 107-109.

[30] Mooney R, Konishi M. Two distinct inputs to an avian song nucleus activate different glutamate receptor subtypes on individual neurons. Proc Natl Acad Sci U S A 1991, 88: 4075-4079.

[31] Mooney R. Synaptic basis for developmental plasticity in a birdsong nucleus. J Neurosci 1992, 12: 2464-2477.

[32] Stark LL, Perkel DJ. Two-stage, input-specific synaptic maturation in a nucleus essential for vocal production in the zebra finch. $\mathrm{J}$ Neurosci 1999, 19: 9107-9116.

[33] Chan CS, Shigemoto R, Mercer JN, Surmeier DJ. HCN2 and HCN1 channels govern the regularity of autonomous pacemaking and synaptic resetting in globus pallidus neurons. J Neurosci 2004, 24: 9921-9932.

[34] Park KH, Meitzen J, Moore IT, Brenowitz EA, Perkel DJ. Seasonallike plasticity of spontaneous firing rate in a songbird pre-motor nucleus. J Neurobiol 2005, 64: 181-191.

[35] Hashimoto K, Kita H. Slow oscillatory activity of rat globus pallidus neurons in vitro. Eur J Neurosci 2006, 23: 443-453.

[36] Solis MM, Perkel DJ. Noradrenergic modulation of activity in a vocal control nucleus in vitro. J Neurophysiol 2006, 95: 2265-2276.

[37] Meitzen J, Moore IT, Lent K, Brenowitz EA, Perkel DJ. Steroid hormones act transsynaptically within the forebrain to regulate neuronal phenotype and song stereotypy. J Neurosci 2007, 27: 12045-12057.

[38] Wood WE, Lovell PV, Mello CV, Perkel DJ. Serotonin, via HTR2 receptors, excites neurons in a cortical-like premotor nucleus necessary for song learning and production. J Neurosci 2011, 31: 13808-13815.

[39] Patlak J. Molecular kinetics of voltage-dependent $\mathrm{Na}^{+}$channels. Physiol Rev 1991, 71: 1047-1080.

[40] Mercer JN, Chan CS, Tkatch T, Held J, Surmeier DJ. Nav1.6 sodium channels are critical to pacemaking and fast spiking in globus pallidus neurons. J Neurosci 2007, 27: 13552-13566.

[41] Perkins KL. Cell-attached voltage-clamp and current-clamp recording and stimulation techniques in brain slices. J Neurosci Methods 2006, 154: 1-18

[42] Ngo-Anh TJ, Bloodgood BL, Lin M, Sabatini BL, Maylie J, Adelman JP. SK channels and NMDA receptors form a $\mathrm{Ca}^{2+}$-mediated feedback loop in dendritic spines. Nat Neurosci 2005, 8: 642-649.

[43] Brosh I, Rosenblum K, Barkai E. Learning-induced modulation of SK channels-mediated effect on synaptic transmission. Eur J Neurosci 2007, 26: 3253-3260.

[44] Faber ES. Functional interplay between NMDA receptors, SK channels and voltage-gated $\mathrm{Ca}^{2+}$ channels regulates synaptic excitability in the medial prefrontal cortex. J Physiol 2010, 588: 1281-1292.

[45] Hahnloser RH, Kozhevnikov AA, Fee MS. An ultra-sparse code underlies the generation of neural sequences in a songbird. Nature 2002, 419: 65-70

[46] Bloodgood BL, Sabatini BL. $\mathrm{Ca}^{2+}$ signaling in dendritic spines. Curr Opin Neurobiol 2007, 17: 345-351.

[47] Bloodgood BL, Sabatini BL. Nonlinear regulation of unitary synaptic signals by $\mathrm{CaV}(2.3)$ voltage-sensitive calcium channels located in dendritic spines. Neuron 2007, 53: 249-260.

[48] Higley MJ, Sabatini BL. Calcium signaling in dendrites and spines: practical and functional considerations. Neuron 2008, 59: 902-913.

[49] Lynch G, Larson J, Kelso S, Barrionuevo G, Schottler F. Intracellular injections of EGTA block induction of hippocampal long-term potentiation. Nature 1983, 305: 719-721.

[50] Bröcher S, Artola A, Singer W. Intracellular injection of $\mathrm{Ca}^{2+}$ chela- 
tors blocks induction of long-term depression in rat visual cortex. Proc Natl Acad Sci U S A 1992, 89: 123-127.

[51] Malenka RC, Lancaster B, Zucker RS. Temporal limits on the rise in postsynaptic calcium required for the induction of long-term po- tentiation. Neuron 1992, 9: 121-128.

[52] Mulkey RM, Malenka RC. Mechanisms underlying induction of homosynaptic long-term depression in area CA1 of the hippocampus. Neuron 1992, 9: 967-975. 